\title{
Children as Mathematicians: The Interplay between Discourse Structure, Mathematicising, and the Participatory Approach
}

\author{
Sinikka Kaartinen and Timo Latomaa \\ University of Oulu, P.O. Box 2000, FI-90014 Oulu, Finland \\ Correspondence should be addressed to Sinikka Kaartinen, sinikka.kaartinen@oulu.fi \\ Received 7 December 2011; Accepted 25 December 2011 \\ Academic Editor: M. Martin
}

Copyright (c) 2012 S. Kaartinen and T. Latomaa. This is an open access article distributed under the Creative Commons Attribution License, which permits unrestricted use, distribution, and reproduction in any medium, provided the original work is properly cited.

\begin{abstract}
This paper investigates the discourse structure, mathematicising and the participatory approach in an early education classroom community whose pedagogy in the learning of mathematics draws on the sociocultural perspective. The social interactions of the classroom community, as well as the role of pre-symbolic sign vehicles as semiotic tools in supporting interaction building, mathematicising, and strategy selection, were subjected to a qualitative micro-level analysis based on applied discourse and semiotic procedures. The results of the study suggest that the young children's mathematical ability develops during the twoyear observation period from nonverbal participation to verbal participation through the following core elements: attention to numeracy, the learning of number words, object counting and mathematical story telling. The iconic and indexical pre-symbolic sign vehicles and semiotic chaining applied in the learning situations provide the learning community with the means to structure their experiences of their everyday practise and to relate them to the culture of mathematicising.
\end{abstract}

\section{Introduction}

Earlier, a semiotic perspective has been applied in school contexts [1], and this study now applies the semiotic perspective in early education classroom contexts. The aim of this paper is to investigate the role of iconic and indexical presymbolic sign vehicles [2] as semiotic tools in mediating children's mathematicising in an early education classroom; the classroom in question is based on the idea of semiotic chaining and collective negotiation of mathematics in a community of learners [3]. The goal of the community is that its participants, consisting of children and educators, collaboratively construct a dialogue for the support of the children's meaningful mathematics learning. In this network, experiences and pedagogical expertise are shared and jointly constructed on the basis of formal and informal observations of the children's mathematical activities across settings and situations.

This study offers an example of emerging mathematical activity, called here mathematicising, where experiences in everyday practise and abstract mathematical content hve been intertwined. This is important, since there has been criticism of the fact that activities of everyday practices differ radically from the mathematical activities of classroom practices [4]. In response to this criticism, this study applies semiotic chaining [5] with the help of properly selected sign vehicles as an instructional model to enhance young children's mathematicising. Semiotic chaining can be interpreted with the help of de Saussure's or Peirce's theories of signs; either as sequences of signifiers or interpretants. In the course of the two-year observation period, the model of semiotic chaining was applied, starting from everyday experiences and practise, continuing to the phase of specific practice characterising this activity, and further to the use of manipulative techniques to represent the specific practise, then finally to the mathematical concept to represent the manipulative. According to earlier research [6], the presence of semiotic tools in instruction and the availability of gestures enable children to communicate even prior to their imitation of the standard discourse of mathematics. In this study, this was realized using iconic and indexical sign vehicles, called here presymbolic signs.

The theoretical and pedagogical background of this paper holds a conception of the child as a cultural and 
historical subject, embedded within and constituted by a network of social relationships and interaction within the culture in question [7-9]. Within this shared conceptual framework, the task of early education mathematics is viewed as giving children opportunities to participate in collective, cultural activities between peripheral and central engagement [10-12]. Through this participation, children position and evaluate themselves as learners of mathematics, and their learner identity is negotiated and renegotiated. The main aim of the early education mathematics classroom described in this paper is to develop a system that nurtures children in developing mathematicising where learning is viewed as a collective negotiation and validation process [13, 14], and where collaboration is used as a tool for building on the participants' interests.

Central to this process is the creation of collective zones of proximal development [15]. Characteristically, these collective zones conceptualise the learner as a participant engaged in collaborative activity within special discourse environments. These zones are mutually and actively created by teachers and children. Semiotic tools constructed and reconstructed in the collective zones create the grounds for meaning making, transforming the human capacity to act, and further develop, cultural contexts [16]. In this process, the all-important semiotic tool is language, which is not understood as a generalised or abstract semiotic system that mediates activity, interaction, and thought, but rather as a multitude of distinct speech genres and semiotic devices that are tightly linked with particular social institutions and with particular social practices [17]. Hence, appropriating the speech or actions of another person requires a degree of identification with that person, and with the cultural community that one represents. Central to this appropriation is the concept of prolepsis $[18,19]$. The concept refers to a communicative move in which the speaker presupposes some as yet unprovided information [20, 21]. According to Rommetveit, the usage of such presuppositions creates a challenge for the listener, a challenge that forces a listener to construct a set of assumptions in order to make sense of the utterance. When the communication is successful, this set of assumptions recreates the speaker's presuppositions. Thus the listener is led to create for himself the speaker's perspective on the topic at issue. To study the possible traces of learning and development in the sociocultural setting then is to study discourse and how it evolves in the flow of social actions. It is the changing nature of these interactions and types of participation that defines learning and development [22]. In addition, modes of thinking evolve as an integral system of motives, goals, values, and beliefs that are closely tied to concrete forms of social practice (see also [17]). It is possible to further conceptualise and clarify the above with sociological discourse theory and with semiotic theory of sign.

Segregated modern and postmodern social practise is founded on different kinds of discourses like the discourse of politics, the discourse of religion, the discourse of business, and, for example, the discourse of everyday small-talk. We call the discourse of politics a certain kind of discourse with its own language, concepts and rules, or discourse principles.
Some discourses are highly specialised, such as the discourse of mathematics containing abstract symbolic signs, language, rules, and principles. Using appropriate discourse moves is one of the rules to promote communication and mutual understanding $[23,24]$. In this paper, we study what kind of discourse moves or conversational exchanges children use, how children learn, and how it is possible to promote and support children's learning and understanding of the discourse of mathematics, or the culture of mathematicising. By tracking discourse moves and the participatory approach, it is possible to understand how general discourse rules-and specific rules of the discourse of mathematics-are learned and used in communication and joint mathematicising.

We use theory of sign to clarify semiotic tools and semiotic chaining used in promoting and supporting interaction building, children's mathematicising, and strategy selection. Peirce's theory of sign [2] is used in its simple form, without referring to his complex theory of universals, ontological categories, and so forth. Peirce distinguishes between three kinds of signs: index, icon, and symbol. He also writes of iconic, indexical, and symbolic dimensions of signs. The index (reagent, designator) is connected to the object it refers to or stands for by rule, principle, or analogy. The icon (image, diagram, metaphor) is similar to the object it refers to. The symbol, like words, is purely a social convention or agreement. Examples of pure icons, indexes, or symbols are rare, but signs in mathematics and in formal logic are closest to pure symbols. Put in other words, most signs have iconic, indexical, and symbolic dimensions, such that every sign can be seen as a combination of index, icon, and symbol. In this study, instead of using symbolic mathematic signs, we used the indexical and iconic properties of visual sign vehicles referring to mathematical concepts and operations to promote and support young children's mathematicising as a mental activity and their learning the discourse of mathematics as a collaborative activity.

\section{The Study and the Method}

In this paper, the collaborative practices of the mathematicising community in the early education classroom are highlighted with case-based descriptions derived from five activities, one from each of five consecutive terms during the observation years 2007-2009.

The specific research questions posed for the study are as follows.

(1) What is the nature of the discourse moves or the conversational exchanges between the members of the early education classroom?

(2) How are semiotic tools applied as meditational means in the participation of the mathematicising community?

(3) What are the core elements of mathematicising in the early education classroom?

In this study the interplay between discourse structures, mathematicising, and the participatory approach will be discussed. 
2.1. Material. The day care centre that participated in the study is a private day care centre located in the northern part of Finland. The pedagogical philosophy of the day care centre consists of partnership-which means close collaboration with parents in child care-and action evaluation and participation, which involves listening to the children's voices in the design and implementation of the curriculum. The usual starting age for the children is two years, and they continue in the day care centre until they start their primary school at the age of six to seven.

Altogether 11 children, their kindergarten teacher, and a university researcher participated in the study. The children, three male and eight female, were two to three years old at the beginning of the 29-month observation period. The kindergarten teacher and the university researcher shared a joint responsibility for the mathematical activity in the classroom community. During the first 12-month observation period, the mathematical activity was taught weekly, and during the second 17 -month period it was taught five times per term. In the project, a research-based instructional emphasis was placed on the role of visual models as strongly iconic or strongly indexical sign vehicles (such as Cuisenaire rods, diverse geometrical models) in supporting the children's mathematical skills. An example of visual models for the number four is presented in Figure 1. Every model in Figure 1 has indexical, iconic, and symbolic dimensions, but (a) is strongly iconic, (b) is strongly indexical, and (c) is symbolic.

The adult members of the preschool learning community studied in this research share joint pedagogical principles (cf., page 7 [25]) in mathematics learning and instruction. In this community, learning is viewed as a collective negotiation process, where collaboration is used as a tool for building on the learners' interests. In these networks, learning activities are constructed by the learners as well as by the teachers and parents. These classrooms are places where the educators engage not only in nurturing the children's learning but are also themselves learners, through their involvement with the other participants of the learning community.

This study draws on videotaped and transcribed data gathered from five joint mathematicising sessions. The classroom interactions are subjected to a qualitative discourse and semiotic analysis in order to investigate, evaluate, and disseminate the pedagogical ideas behind the classrooms. In the first three activities, the applied mathematical big book was The Fluffy Ducks by Jill Bever and Sheilah Currie, with illustrations by Barbara Spurll, published by ETA/Cuisenaire, 2005. From the semiotic point of view, this book uses visual signs with strong indexical and iconic dimensions rather than pure mathematical symbols to present mathematical concepts and operations. The first learning activity described in this study was videotaped in the autumn term 2007, and it represents the mathematical activity at a time when the big book was novel and the children were not familiar with its content. The second learning activity described in this study was videotaped in the spring term 2008 , and the third during the autumn term 2008. The fourth learning activity was videotaped in the spring term 2009, and the fifth in the autumn term 2009. The selection of these episodes is based on the research idea which tries to trace the development of child participation in mathematicising and the development of children's mathematical thinking and learning of the discourse of mathematics. The university researcher and the kindergarten teacher participated as teacher-researchers in these mathematical sessions.

2.2. Method. The discourse analysis procedure $[26,27]$ assisted by semiotic theory which is applied in this study to investigate the nature of mathematicising activity in the early education classroom draws on an approach in which the key unit of analysis is a situation, that is, a segment of social life in a classroom [24]. The semiotic theory of dyadic sign [28] is used to clarify an analytic distinction between videotaped and transcribed data as sign vehicle and their meaning content as interpreted and explicated by researchers. The interaction data set selected here focuses thematically on the usage of semiotic tools in the early education classroom and consists of videotaped and transcribed episodes of social interaction in the early education classroom described above. The analytical framework developed for this study focuses on three dimensions, namely, on discourse moves, mathematicising, and the participatory approach.The categories characterising discourse moves are adapted from the framework developed by Sinclair and Coulthard [29]. However, in this study, the structure of the pedagogical discourse is more multidimensional than the Initiation-Reply-Evaluation exchange described by Sinclair and Coulthard [29, page 21]. The analysis of discourse moves highlights the nature of conversational exchanges between the members of the early education classroom and consequently sheds light on the interactional roles of the members engaged in mathematicising activity. Social interaction is based on an interplay between different kinds of discourses. The analysis of the mathematicising category sheds light on the mathematical ability of the child as it emerges in social interaction, and the participatory approach makes visible the social and mental strategies which emerge in the course of social interaction.

In order to develop the analysis to investigate the collaborative inquiry and the activity construction in the early education classroom, the data were analysed in several phases. Firstly, the video material capturing the social activity of the classroom in question was closely examined and reflected upon. Next the discourse occurring in the classroom during the course was transcribed. The analytic categories were constructed from the interaction data of the study, on the basis of the transcriptions, supported by the video data. Although the code names of the analytic categories represent context-free codes, the meaning behind the code names has been contextually defined to represent the interaction data of this study. The application of the coding scheme is realised through the microanalysis of the evolving classroom interaction by focusing on each conversational turn, using mutually exclusive and exhaustive categories.

2.3. Specifications of the Analytic Dimensions. Discourse moves identified in the data are accepting, answering, 


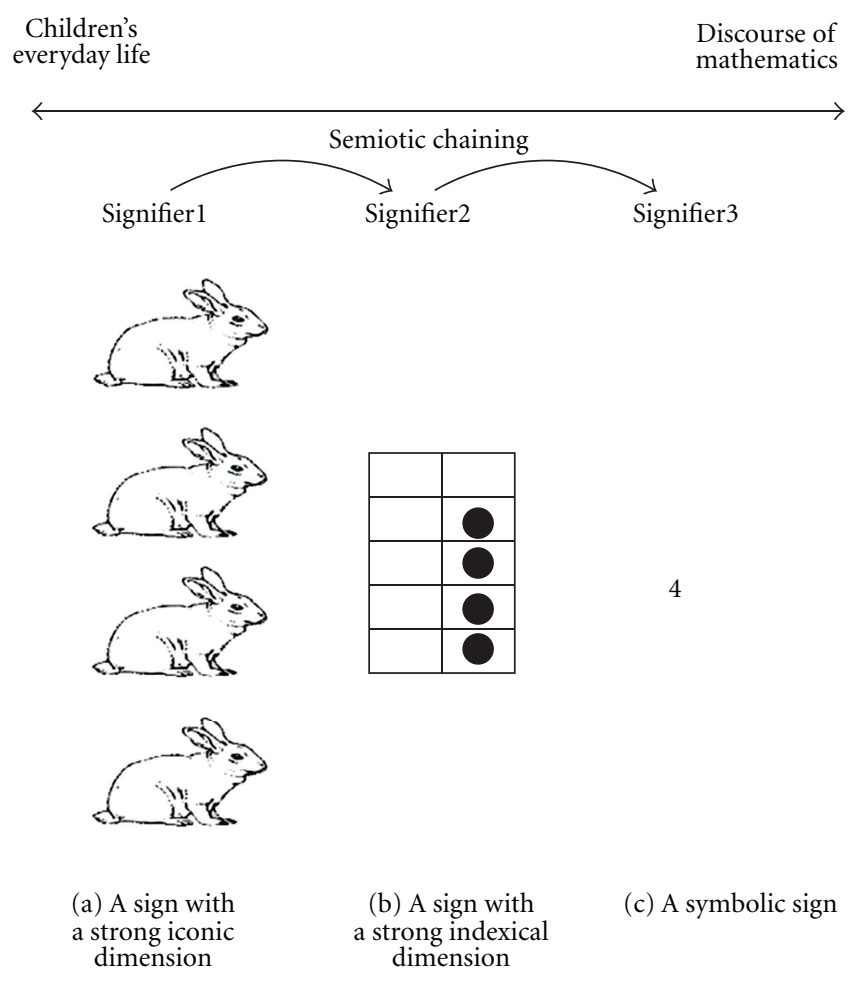

Figure 1: Example of visual models for the number four.

commenting, continuing counting, questioning, extending, initiating, tutoring, and nonverbal participation. The content of the discourse moves was further analysed according to forms of participation. The analysis of the content of the discourse moves revealed forms of participatory approach, namely types of mathematicising strategy and interaction building. Mathematicising strategies found in the data are evaluation, touching the ducks one by one, pointing at each duck one by one and counting orally, counting the first five dips in the ten-egg carton and then the second five dips, storytelling, and mathematical storytelling and subitising. Interaction building types found in the data are suggesting a participatory turn, giving a participatory turn, and taking a participatory turn. Furthermore, interpretation of the content of the discourse moves highlights the emergence of mathematical activity such as attention to quantity, oneto-one correspondence between a number and the quantity, number sequencing, recognition of a written symbol for a quantity, an addition task, and a subtraction task. In the interest of reliability in the interpretation and coding of the social interaction of the group, the data have been analysed independently by two different researchers (one mathematics educator and one researcher in educational sciences); diverse opinions have been negotiated to establish joint agreement, the construction of which has been guided when necessary by domain-specific knowledge of early years' mathematics. Table 1 summarises the analytic frames and categories of the analysis method.

\section{The Results}

The results will next be discussed with case-based descriptions. In the first activity; the applied mathematical big book was The Fluffy Ducks by Jill Bever and Sheilah Currie, with illustrations by Barbara Spurll, published by ETA/Cuisenaire, 2005. The mathematical big book used in this study integrates with children's stories the basic concepts presented by indexical and iconic visual signs for the learning of the number names. Attractive illustrations and a familiar story line rich in mathematical content create a fun, engaging, and effective learning resource for children (see Table 2).

In this activity, the teacher directs the children's attention to quantities by asking: "how many ducks do you see there?" Elli expresses her willingness to participate by evaluating her knowledge in counting: "yes I know how to count yes I know how to count." Kalle understands the teacher's question and counts the number of ducks non-verbally by pointing at the ducks one-by-one. This leads Inka also to nonverbal participation and she indicates the number of ducks by pointing. Elli evaluates the non-verbal participation by saying, "you do not count like that you do not count like that" and Antti would like to count the number of ducks and he asks, "can I count." The teacher encourages Kalle towards verbal participation by saying, "now it is Kalle's turn to count." Elli arrives at her solution and takes her turn to participate by counting, "one, two, three, four, five." The teacher accepts 
TABLE 1: The method of analysis for mathematicising activity.

\begin{tabular}{|c|c|c|c|}
\hline \multirow{2}{*}{ Discourse moves } & \multirow{2}{*}{ Mathematicising } & \multicolumn{2}{|c|}{ Participatory approach } \\
\hline & & Mathematicising strategy & Interaction building \\
\hline (i) accepting & (i) attention to quantity & (i) evaluation & (i) suggesting a participatory turn \\
\hline (ii) answering & (ii) number sequencing & (ii) touching ducks one by one & (ii) giving a participatory turn \\
\hline (iii) commenting & $\begin{array}{l}\text { (iii) one-to-one correspondence } \\
\text { between a number and the quantity }\end{array}$ & $\begin{array}{l}\text { (iii) pointing at each duck one } \\
\text { by one and counting orally }\end{array}$ & (iii) taking a participatory turn \\
\hline (iv) continuing & $\begin{array}{l}\text { (iv) recognising a written symbol to a } \\
\text { quantity }\end{array}$ & $\begin{array}{l}\text { (iv) counting the first five dips } \\
\text { in a ten-egg carton and then } \\
\text { the second five dips }\end{array}$ & \\
\hline (v) counting & (v) addition task & (v) story telling & \\
\hline (vi) questioning & (vi) subtraction task & (vi) mathematical story telling & \\
\hline (vii) extending & & (vii) subitising & \\
\hline (viii) initiating & & (viii) counting mentally & \\
\hline \multicolumn{4}{|l|}{ (ix) tutoring } \\
\hline (x) nonverbal part & & & \\
\hline
\end{tabular}

TABLE 2: Joint big book reading and mathematicising (videotaped in the autumn term 2007).

\begin{tabular}{|c|c|c|c|c|c|}
\hline No. & name & Social interaction & $\begin{array}{l}\text { Discourse } \\
\text { moves }\end{array}$ & Mathematicising & Participatory approach \\
\hline 1 & teacher & how many ducks do you see there & questioning & attention to quantities & \\
\hline 4 & Elli & $\begin{array}{l}\text { yes I know how to count } \\
\text { yes I know how to count }\end{array}$ & initiating & & evaluation \\
\hline 5 & Kalle & nonverbal participation & continuing & & touches ducks one by \\
\hline 6 & Inka & nonverbal participation & & & one \\
\hline 7 & Elli & $\begin{array}{l}\text { you do not count like that } \\
\text { you do not count like that }\end{array}$ & commenting & & evaluation \\
\hline 8 & Antti & can I count & questioning & & \\
\hline 9 & teacher & now it is Kalle's turn to count & tutoring & & \\
\hline 10 & Elli & one, two, three, four, five & counting & $\begin{array}{l}\text { one-to-one correspondence } \\
\text { between a number and the quantity }\end{array}$ & $\begin{array}{l}\text { points to each duck one } \\
\text { by one and counts orally }\end{array}$ \\
\hline 11 & teacher & okay & accepting & & \\
\hline 12 & Inka & one & continuing & & \\
\hline
\end{tabular}

Elli's solution by saying "okay" and Elli's example encourages Inka too to count out loud and she starts counting by saying "one."

This example demonstrates that the signs with strong indexical and iconic dimensions used in the teaching material can be applied to guide children's attention to quantities; the children's response can be either non-verbal, counting by pointing at each one of the objects, or verbal counting where the number names are produced orally and the mathematical content of the participation is the one-to-one correspondence between a number and the quantity.

In this phase of instruction, the everyday activity can be interpreted as the school life of ducks, and visual signs with strong indexical and iconic dimensions for the number five can be interpreted as a manipulative to represent the specific practice. The developmental path of the child in mathematicising can be sketched as a progression from the narrative function of a gesture to its grounding function, as the cases of Inka and Elli demonstrate.
In the second activity, represented in Table 3, the community continues the same big book reading in the next term, videotaped in the spring term 2008.

In this activity, the teacher again starts by directing the children's attention to quantities by saying, "I have a great puzzle for you, look how many ducks there are in the picture." Inka answers by counting, "one, two, three, four, five." Here Inka's counting process refers to number sequencing because she continues the number naming after the quantified number four. Antti starts tutoring by saying: "first Selma" and Selma counts, "one, two, three, four." In her turn, Selma perceived the one-to-one correspondence between a digit and the quantity. Then Antti continues by saying, "then me" but Inka is also willing to count and starts, "one." However, Antti has decided that it is his turn and he takes it by saying, "I have to, one, two, three, four." Antti's turn also reflects the understanding of a one-to-one correspondence between a digit and quantity. 
TABLE 3: Counting the book characters and the quantity of objects.

\begin{tabular}{|c|c|c|c|c|c|}
\hline No. & Name & Social interaction & Discourse moves & Mathematicising & Participatory approach \\
\hline 1 & teacher & $\begin{array}{l}\text { I have a great puzzle for you, look how } \\
\text { many ducks there are in the picture }\end{array}$ & questioning & attention to quantities & \\
\hline 2 & Inka & one, two, three, four, five, & counting & number sequencing & $\begin{array}{l}\text { points to each one, one } \\
\text { by one, and counts } \\
\text { orally }\end{array}$ \\
\hline 3 & Antti & first Selma & tutoring & & $\begin{array}{l}\text { giving participatory } \\
\text { turn }\end{array}$ \\
\hline 4 & Selma & one, two, three, four & counting & $\begin{array}{l}\text { one-to-one correspondence } \\
\text { between a number and the } \\
\text { quantity }\end{array}$ & $\begin{array}{l}\text { points to each one, one } \\
\text { by one, and counts } \\
\text { orally }\end{array}$ \\
\hline 5 & Antti & then me & tutoring & & $\begin{array}{l}\text { giving participatory } \\
\text { turn }\end{array}$ \\
\hline 6 & Inka & I should, one & counting & & $\begin{array}{l}\text { suggesting } \\
\text { participatory turn }\end{array}$ \\
\hline 7 & Antti & I have to, one, two, three, four & & $\begin{array}{l}\text { one-to-one correspondence } \\
\text { between a number and } \\
\text { quantity }\end{array}$ & $\begin{array}{l}\text { taking a participatory } \\
\text { turn }\end{array}$ \\
\hline
\end{tabular}

TABLE 4: Story telling and mathematicising.

\begin{tabular}{|c|c|c|c|c|c|}
\hline \multicolumn{2}{|c|}{ No. Name } & \multirow{2}{*}{$\begin{array}{l}\text { Social interaction } \\
\text { a bus is travelling with those ducks }\end{array}$} & \multirow{2}{*}{$\begin{array}{l}\text { Discourse moves } \\
\text { initiating }\end{array}$} & \multirow[t]{2}{*}{ Mathematicising } & \multirow{2}{*}{$\begin{array}{l}\text { Participatory approach } \\
\text { story telling }\end{array}$} \\
\hline 1 & Selma & & & & \\
\hline 2 & Kalle & and there is a pig who is driving & continuing & & \\
\hline 3 & Elli & me me me me & initiating & & \\
\hline 4 & Veli & handing the book to Elli & non-verbal participation & & giving a turn \\
\hline 5 & Elli & $\begin{array}{l}\text { okay here is one duck and there are three ducks } \\
\text { skating }\end{array}$ & extending & attention to quantities & subitising \\
\hline 6 & Selma & on the road for cars & continuing & & story telling \\
\hline 7 & Elli & Alma will start & tutoring & & giving a turn \\
\hline
\end{tabular}

This activity shows that Inka had developed her nonverbal participation to number sequencing, as she now uses her skill in order to count the number of objects.

In the next activity, presented in Table 4, the children again read the same big book. This example is videotaped in the autumn term 2008.

Here Selma initiates by storytelling, saying, " $a$ bus is travelling with those ducks" and Kalle continues by saying, "and there is a pig who is driving." Elli initiates by suggesting her participation, "me me me me." This leads Kalle to hand the book to Elli, who extends the interaction to mathematicising by subitising and storytelling, "okay here is one duck and there are three ducks skating." Selma continues the story by adding, "on the road for cars," and Elli tutors by giving a turn to Alma, saying, "Alma will start."

In this activity, the children collaborate by themselves. This activity shows that the children do not necessarily pay attention to quantities in their social interactions without the adult guidance, although the learning material provides signs in visual modelling. In Elli's turn, there is mathematical content and she is able to subitise in the situation correctly.

Elli's developmental path shows that her mathematical ability has developed from object counting to that of subitising in the number area of four.
In the next activity, presented in Table 5, household materials such as egg-cartons are applied as semiotic tools.

This activity starts by the teacher questioning, "okay so how many go here?" and Elli subitises "six.” Inka checks Elli's solution by counting, "one, two, three, four, five, six." Here we observe that Inka's number sequencing ability (see Table 3 for comparison) has developed to systematic counting, where there is one-to-one correspondence between a digit and the quantity. Then the teacher continues with an addition task: "if four go here and six go here, so how many altogether?" Inka answers by counting, "one, two, three, four, five, six, seven, eight, nine, ten." In her solution, Inka uses the egg-carton model as a box for counting to ten, she starts by counting the first five dips in the box and then the second five dips. The teacher extends the interaction by connecting the number of objects to the written symbol for the quantity by questioning, "okay good, what about, there are balloons there, so how many are there, it has been marked with a (written) number, can you find it?" Elli answers by saying, "eight." In her turn, Elli shows that she recognises the written symbol for a quantity.

This activity shows that Inka's developmental path has moved from non-verbal participation through number sequencing to object counting. Elli, at her current stage, is able 
TABLE 5: Mathematicising during the Mayday holiday period, videotaped in spring term 2009.

\begin{tabular}{|c|c|c|c|c|c|}
\hline No. & Name & Social interaction & Discourse moves & Mathematicising & Participatory approach \\
\hline 6 & visiting-teacher & okay so how many go here & questioning & attention to quantity & \\
\hline 7 & Elli & $\operatorname{six}$ & answering & & subitising \\
\hline 8 & Inka & one, two, three, four, five, six & counting & $\begin{array}{l}\text { One-to-one correspondence } \\
\text { between a number and } \\
\text { quantity }\end{array}$ & \\
\hline 9 & visiting-teacher & $\begin{array}{l}\text { if four go here and six go here, so } \\
\text { how many altogether }\end{array}$ & questioning & attention to quantity & \\
\hline 10 & Inka & $\begin{array}{l}\text { one, two, three, four, five, six, seven, } \\
\text { eight, nine, ten }\end{array}$ & counting & $\begin{array}{l}\text { One-to-one correspondence } \\
\text { between a number and } \\
\text { quantity }\end{array}$ & $\begin{array}{l}\text { counting the first five } \\
\text { dips in a ten-egg carton } \\
\text { and then the second } \\
\text { five dips }\end{array}$ \\
\hline 11 & visiting-teacher & $\begin{array}{l}\text { okay good, what about, there are } \\
\text { balloons there, so how many are } \\
\text { there, it has been marked with a } \\
\text { (written) number, can you find it }\end{array}$ & questioning & & \\
\hline 12 & Elli & eight & answering & $\begin{array}{l}\text { recognising a written symbol } \\
\text { for quantity }\end{array}$ & \\
\hline 13 & visiting-teacher & okay & accepting & & \\
\hline
\end{tabular}

TABLE 6: Mathematical story for the visual model.

\begin{tabular}{|c|c|c|c|c|c|}
\hline No. & Name & Social interaction & Discourse move & Mathematicising & Participatory approach \\
\hline 6 & Kalle & I have four & initiating & $\begin{array}{l}\text { one to one } \\
\text { correspondence between } \\
\text { a digit and quantity }\end{array}$ & mathematical story telling \\
\hline 7 & visiting-teacher & yes, and what about that, then & commenting & & \\
\hline 8 & Kalle & if I added six it would make I do not know & continuing & addition task & \\
\hline 9 & visiting-teacher & $\begin{array}{l}\text { yes you said that you have four, and if you } \\
\text { add six it will make ten }\end{array}$ & extending & & \\
\hline 10 & visiting-teacher & okay good Inka & initiating & & \\
\hline 11 & Inka & I have here six & continuing & & subitising \\
\hline 12 & visiting-teacher & yes, will you tell us something else & questioning & & \\
\hline 13 & Inka & noo & extending & & \\
\hline 14 & visiting-teacher & $\begin{array}{l}\text { it is a good story with six, you can tell a } \\
\text { little bit more next time, okay Selma }\end{array}$ & commenting & & \\
\hline 15 & Selma & $\begin{array}{l}\text { I have ten, if I subtracted those I would } \\
\text { have four and if I subtracted those I would } \\
\text { have six }\end{array}$ & continuing & $\begin{array}{l}\text { one-to-one } \\
\text { correspondence between } \\
\text { a digit and quantity }\end{array}$ & subtraction task \\
\hline 16 & visiting-teacher & okay Elli & initiating & & \\
\hline 17 & Elli & eight & answering & $\begin{array}{l}\text { one-to-one } \\
\text { correspondence between } \\
\text { a digit and quantity }\end{array}$ & subitising \\
\hline 18 & visiting-teacher & hmm & commenting & & \\
\hline 19 & Elli & if I subtracted these two I would have six & continuing & subtraction task & counting mentally \\
\hline 20 & visiting-teacher & oh-hoh what about alma & commenting & & \\
\hline 21 & Alma & I have now seven if I subtracted & initiating & subtraction task & \\
\hline 22 & visiting-teacher & yes & commenting & subtraction task & \\
\hline
\end{tabular}

to subitise up till six and make a connection between the number eight and its written symbol.

In the next activity, presented in Table 6, the children tell a mathematical story of the objects in the counting ten box that is represented visually. The situation is videotaped during the autumn term 2009.
Here Kalle starts by saying, "I have four" and the teacher comments, "yes, and what about that, then" and Kalle continues, "if I added six it would make I do not know" and the teacher continues, "yes you said that you have four, and if you add six it will make ten." Here Kalle subitises that there is six missing in his counting ten box but he is not yet able to 
count the total. Next the teacher invites Inka to participate by saying, "okay good Inka" and Inka continues: "I have here six." The teacher questions "will you tell us something else?" and Inka answers "noo." The teacher comments on Inka's hesitation by saying "it is a good story with six you can tell a little bit more next time, okay Selma." Selma continues by saying: "I have ten, if I subtracted those I would have four and if I subtracted those I would have six." In her turn Selma models two subtraction situations. Then the teacher gives the turn to Elli and answers, "eight" and Elli continues, "if I subtracted these two I would have six" and the teacher comments, "ohhoh what about Alma" and Alma initiates "I have now seven if I subtracted..." and the teacher accepts by saying yes.

This example demonstrates that Inka has developed from nonverbal participation through number sequencing and object counting to a subitising level in her mathematical thinking. Elli is able to construct a subtraction task on the basis of signs that are less indexical and iconic and closer to symbolic signs and count it mentally.

\section{Discussion and Conclusions}

The results of the study suggest that these children are eager and able to participate in mathematicising activity that is grounded on the instructional usage of semiotic chaining and indexical and iconic signs closer to their way of thinking and mental capacity. From the social and mental perspectives, the teacher role in guiding the participation becomes crucial. The children's eagerness in participation can raise social conflicts that need to be resolved within the learning community. It should also be noted that children do not necessarily pay attention to the quantifying property of the model without teacher guidance.

The results of the study suggest that the usage of proper signs as semiotic tools in guiding participation supported diverse social roles such as initiator, extender, executor, and evaluator. In this study, the teacher had an active role as an initiator in guiding child attention to quantities. A child in participation can be viewed as an executor of the activity in question when continuing the teacher initiation. However, the children participated also as evaluators, tutors, initiators, and extenders.

The mathematical activity, of the children varied across situations. In mathematicising, the children's participation moved from non-verbal participation to that of verbal participation. In verbal participation, they paid attention to quantities, used number sequencing in counting the number of objects, and found one-to-one correspondences between a number and the quantity. In the story telling activity, they constructed addition and subtraction tasks and counted the solution for them mentally.

This study in the participatory approach deals with content and with the mental and social strategies which the children chose. The signs applied in this study-mediated mathematical story telling, subitising, and connection building between a quantity and a written symbol. The children used metacognition in evaluating the nature of participation, and they used cognitive benchmarks such as pointing and touching the object when counting. Furthermore, they applied the mathematical model of grouping in fives when counting the number of ten objects. The social strategies that the children selected were giving participatory turns, suggesting participatory turns and taking participatory turns.

On the whole, this study suggests that educational interaction grounded on semiotic chaining in mathematics and the choosing of appropriate signs in mediating mathematicising activity offered an educationally rich environment in the early education classroom described in this study. Multidimensionality was seen in diverse social roles, making visible the core elements of the young children's mathematical ability development, and diverse social and mental strategies emerged in the interaction. To conclude, signs with indexical and iconic dimensions applied in the learning situations provided the children with the means to structure their experiences of their living environment and to relate them to the culture of mathematicising. The role of the teacher then is to help children to see the culture of mathematics in the world around them and to support the children's personal growth in the area of mathematics.

This study makes visible the nature of educational interaction as regards orientation towards mathematics which is possible in the early education classroom. From the educator's point of view, the educational interaction investigated in this study requires expertise in mathematics pedagogy, knowledge of the child, and application of semiotics. These are not the questions typically resolved in instructional methods for teaching mathematics in early education classrooms. In this study, these questions were approached in close collaboration between an early childhood educator and an expert in mathematics pedagogy.

The present study challenges early childhood education programs to take into account the nature and role of mathematics in the pedagogy of young children. This study brings in the dual nature of learning in early mathematics: on the one hand, the mediational role of semiotic vehicles in raising the numerical awareness of young children and on the other hand, the teacher's ability to assist the child in building up the meanings for mathematics in everyday life.

\section{References}

[1] A. Sáenz-Ludlow and N. Presmeg, "Semiotic perspectives on learning mathematics and communicating mathematically," Educational Studies in Mathematics, vol. 61, no. 1-2, pp. 1-10, 2006.

[2] C. S. Peirce, "Logic as Semiotic; The Theory of Sign," in The Philosophy of Peirce, Selected Writings, J. Buchler, Ed., pp. 98119, Routledge, London, UK, 2000, (orig. 1940).

[3] P. Cobb and H. Bauersfeld, "Introduction: the coordination of psychological and sociological perspectives in mathematics education," in The Emergence of Mathematical Meaning. Interaction in Classroom Cultures, $\mathrm{P}$. Cobb and H. Bauersfeld, Eds., pp. 1-17, Lawrence Erlbaum Associates, Hillsdale, NJ, USA, 1995.

[4] N. Presmeg, "Semiotics and the "connections" standard: significance of semiotics for teachers of mathematics," Educational Studies in Mathematics, vol. 61, no. 1-2, pp. 163-182, 2006. 
[5] M. Hall, Bridging the gap between everyday and classroom mathematics: an investigation of two teachers' intentional use of semiotic chains, Ph.D. Dissertation, Florida State University, 2000.

[6] W. M. Roth, "Gestures: their role in teaching and learning," Review of Educational Research, vol. 71, no. 3, pp. 365-392, 2001.

[7] L. S. Vygotsky, in Thought and Language, E. Hanfmann and G. Vakar, Eds., MIT Press, Cambridge, Mass, USA, 1962.

[8] L. S. Vygotsky, in Mind in Society: the Development of Higher Mental Processes, M. Cole, V. John-Steiner, and E. Souberman, Eds., Harvard University Press, Cambridge, Mass, USA, 1978.

[9] J. Wertsch, Voices of the Mind: A Sociocultural Approach to Mediated Action, Harvard University Press, Cambridge, Mass, USA, 1991.

[10] B. Rogoff, "Developing understanding of the idea of communities of learners," Mind, Culture, and Activity, vol. 1, no. 4, pp. 209-229, 1994.

[11] J. Lave and E. Wenger, Situated Learning. Legitimate Peripheral Participation, Cambridge University Press, Cambridge, UK, 1991.

[12] G. Wells, Dialogic Inquiry, Towards a Sociocultural Practice and Theory of Education, Cambridge University Press, Cambridge, UK, 1999.

[13] T. P. Carpenter, E. Fennema, P. L. Peterson, C. P. Chiang, and M. Loef, "Using knowledge of children's mathematics thinking in classroom teaching: an experimental study," American Educational Research Journal, vol. 26, no. 4, pp. 499-531, 1989.

[14] M. Lampert, "When the problem is not the question and the solution is not the answer: mathematical knowing and teaching," American Educational Research Journal, vol. 27, no. 1, pp. 29-63, 1990.

[15] L. C. Moll and K. F. Whitmore, "Vygotsky in classroom practice: moving from individual transmission to social transaction," in Contexts for Learning. Sociocultural Dynamics in Children's Development, E. A. Forman, N. Minick, and C. A. Stone, Eds., pp. 19-42, Oxford University Press, New York, NY, USA, 1993.

[16] L. Martin, K. Nelson, and E. Tobach, Eds., Sociocultural Psychology. Theory and Practice of Doing and Knowing, Cambridge University Press, Cambridge, UK, 1995.

[17] N. Minick, C. A. Stone, and E. A. Forman, "Integration of individual, social, and institutional processes in accounts of children's learning and development," in Contexts for Learning. Sociocultural Dynamics in Children's Development, E. A. Forman, N. Minick, and C. A. Stone, Eds., pp. 3-16, Oxford University Press, New York, NY, USA, 1993.

[18] C. A. Stone, "Vygotsky's developmental model and the concept of proleptic instruction: some implications for theory and research in the field of learning disabilities," Research Communications in Psychology, Psychiatry and Behavior, vol. 10, no. 1-2, pp. 129-152, 1985.

[19] C. A. Stone and J. V. Wertsch, "A social interactional analysis of learning disabilities remediation," Journal of Learning Disabilities, vol. 17, no. 4, pp. 194-199, 1984.

[20] R. Rommetveit, On Message Structure: A Framework for the Study of Language and Communication, John Wiley \& Sons, New York, NY, USA, 1974.

[21] R. Rommetveit, "On codes and dynamic residuals in human communication," in Studies of Language, Thought and Verbal Communication, R. Rommetveit and R. M. Blakar, Eds., pp. 163-175, Academic Press, Orlando, Fla, USA, 1979.

[22] M. Goos, P. Galbraith, and P. Renshaw, "Establishing a community of practice in a secondary mathematics classroom," in Learning Mathematics: From Hierarchies to Networks, L. Burton, Ed., Studies in Mathematics Education Series 13, pp. 36-61, Falmer Press, London, UK, 1999.

[23] J. P. Gee, An Introduction to Discourse Analysis: Theory and Method, Routledge, London, UK, 1999.

[24] J. P. Gee and J. L. Green, "Discourse analysis, learning, and social practice: a methodological study," Review of Research in Education, vol. 23, pp. 119-169, 1998.

[25] B. Rogoff, C. G. Goodman-Turkanis, and L. Bartlett, Learning Together. Children and Adults in a School Community, Oxford University Press, New York, NY, USA, 2001.

[26] S. Kaartinen and K. Kumpulainen, "Negotiating meaning in science classroom communities: cases across age levels," Journal of Classroom Interaction, vol. 36, pp. 4-16, 2001.

[27] S. Kaartinen, "Meaningfulness via participation: sociocultural practices for teacher learning and development," Teachers and Teaching: Theory and Practice, vol. 15, no. 5, pp. 601-616, 2009.

[28] F. de Saussure, Courses in General Linguistics, Translated from Cours de Linguistique Générale by R. Harris 1916, Duckworth, London, UK, 3rd edition, 2005.

[29] J. M. Sinclair and R. M. Coulthard, Towards an Analysis of Discourse. The English Used by Teachers and Pupils, Oxford University Press, London, UK, 1975. 

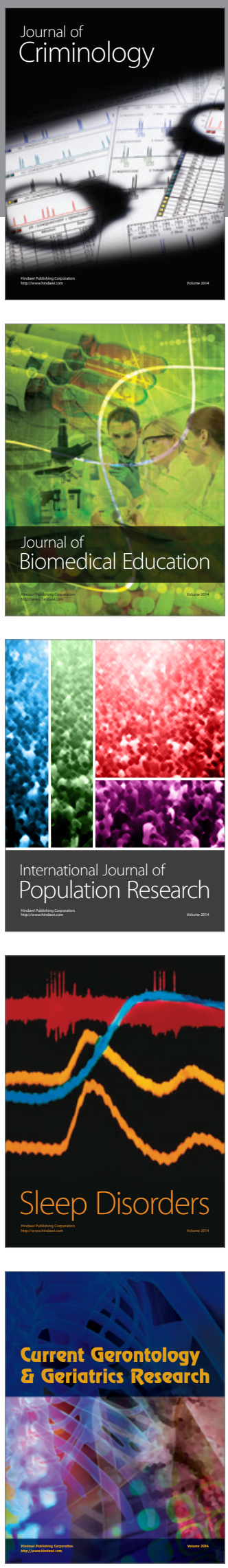
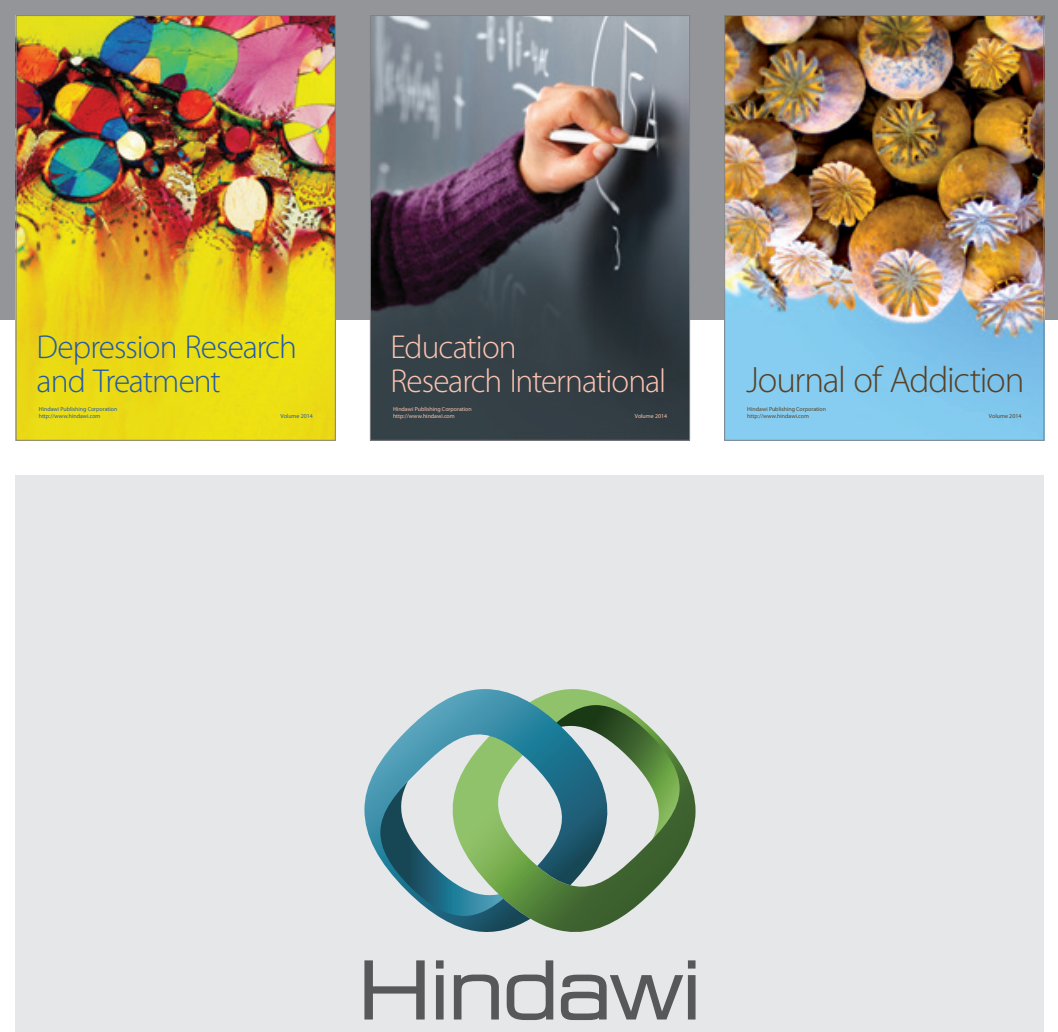

Submit your manuscripts at

http://www.hindawi.com

Child Development Research
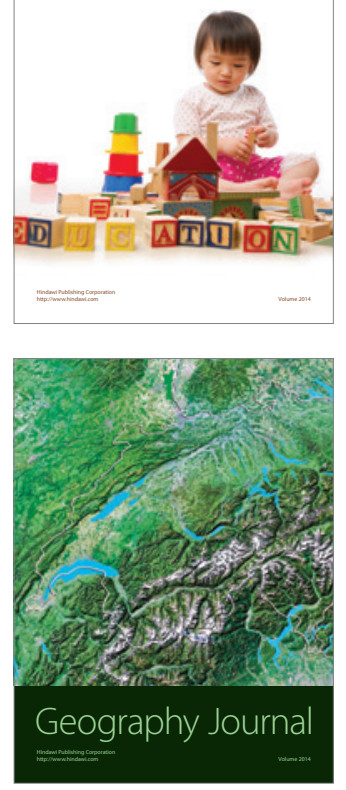

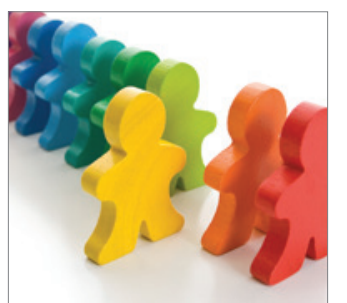

Autism

Research and Treatment
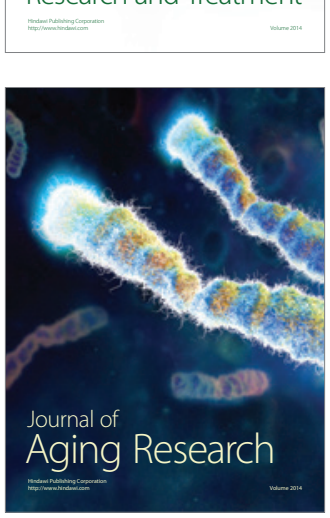
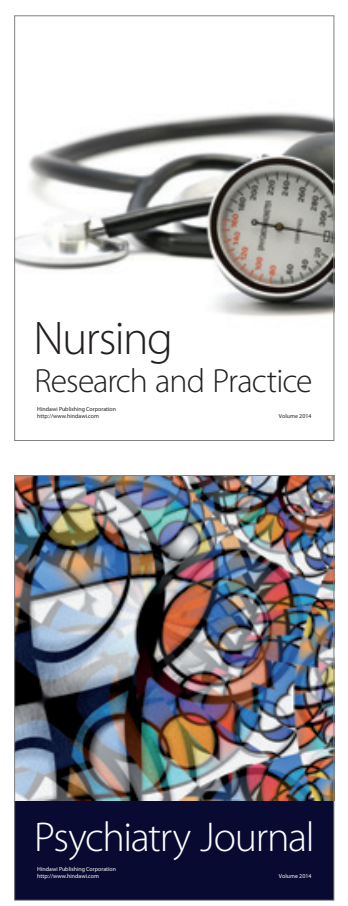
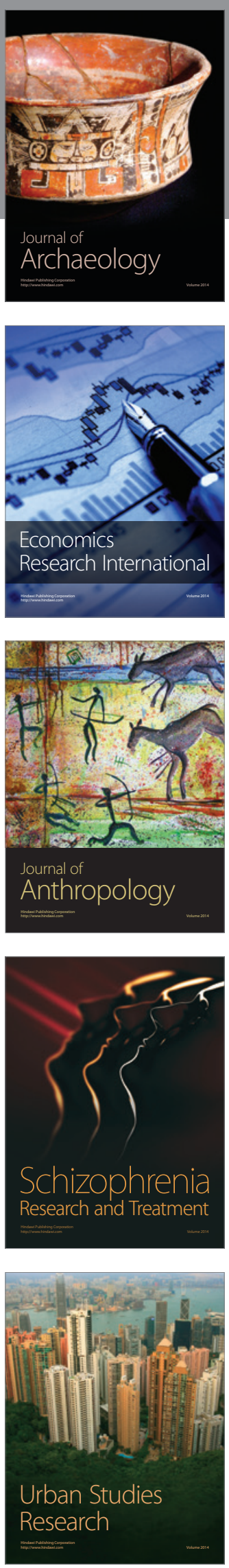